\title{
GUIDELINES FOR THE DIAGNOSIS OF THE HAEMOGLOBINOPATHIES IN NIGERIA
}

\author{
Taiwo R. Kotila
}

Department of Haematology, University of Ibadan, Nigeria

Correspondence:

Dr. T.R. Kotila

Department of Haematology, University College Hospital, PMB 5116, Ibadan, Nigeria

Email: tkotila@comui.edu.ng

\begin{abstract}
The haemoglobinopathies are prevalent genetic disorders in Nigeria, it is therefore imperative that diagnosis is made accurately and promptly so that affected individuals can seek timely medical help. There is no structured modality for the investigation of the haemoglobinopathies in the country. Haemoglobin electrophoresis at alkaline $\mathrm{pH}$ is solely relied upon by both the secondary and tertiary health centres in the diagnosis of the haemoglobinopathies. It is also necessary to know and understand the various diagnostic tests available for this genetic disorder and to interpret the results correctly. This review discusses the different diagnostic tests appropriate for the different levels of health care in the country.
\end{abstract}

\section{INTRODUCTION}

The haemoglobinopathies are a group of inherited disorders of haemoglobin synthesis and are divided into five broad groups which include, structural (qualitative), quantitative (Thalassaemias), unstable haemoglobins, haemoglobins with low oxygen affinity and the $\mathrm{M}$ haemoglobins which are associated with familial cyanosis while haemoglobins with high oxygen affinity are associated with erythrocytosis (polycythaemia). Accurate diagnosis of the haemoglobinopathies is necessary in this environment not because it is a prevalent condition but also because even though there are over 400 haemoglobin variants not all are symptomatic. Most haemoglobinopathies are due to one or two amino acid substitutions thus affecting the mobility of the haemoglobin on electrophoresis. This aids easy diagnosis of these disorders. There are a number of clinically significant haemoglobins which do not alter the overall charge of the protein so are detected by other methods other than electrophoresis, e.g. isoelectric focusing, high- performance liquid chromatography (HPLC), and immunologic techniques.

Sickle cell disease (SCD) is a haemoglobinopathy with structural defect and it is very common in Nigeria. The prevalence of homozygous SCD (HbSS) and $\mathrm{HbS}+\mathrm{C}$ disease is $3.1 \%$ and $1.1 \%$ respectively thus giving a combined prevalence of $4.1 \%$ while the trait (HbAS) has a prevalence of $23.7 \%$. This high prevalence requires that accurate diagnosis of the disorder is made, not only at the tertiary hospitals but also at the secondary level while primary health centres should be able to screen patients for the disorder.
The thalassaemias are quantitative disorders of haemoglobin synthesis which are classified into two; the alpha and the beta thalassaemias. The single deletion alpha thalassaemia which is common ${ }^{2}$ in this environment is the mild type but beta thalassaemia which is of more clinical significance was initially thought to be of low prevalence ${ }^{3}$ but it is now known to be of high prevalence ${ }^{4,5}$. There is therefore the need to be able to differentiate these various haemoglobinopathies and treat the patients' accordingly. Accurate diagnosis will also prevent subjecting the patients to unnecessary investigations.

The objective of this write up is to provide a guideline for the screening and diagnosis of the haemoglobinopathies in the Nigerian setting and to delineate what tests are appropriate for the different level of health care.

\section{Patient Selection}

Patients who present with unexplained anaemia should be screened for haemoglobinopathy and it should be mandatory to rule out a haemoglobinopathy especially in patients presenting with moderate or severe anaemia in the presence of jaundice ${ }^{5}$. Patients noticed to have microcytosis and hypochromia on blood film review, should be investigated for thalassaemia more so if a trial of iron therapy does not correct this blood film appearance. The nation is however ripe for newborn screening of these prevalent disorders; this will help in reducing the morbidity and mortality associated with them. 


\section{Screening Tests}

Microscopy: A review of the peripheral blood film is a good initial screening test, the presence of target cells and sickled erythrocyte or microcytic cell is a pointer to sickle cell disease or thalassaemia respectively.

Sickling test. This is a simple screening test that can be done especially in a primary health care facility. A drop of blood is mixed with two drops of $2 \%$ sodium metabisulphite, this is then covered with a coverslip and sealed with petroleum jelly. The slide is then examined under the microscope after 15 minutes, one hour and 24 hours $^{6}$. The presence of sickled erythrocytes in a patient with symptoms of sickle cell disease is suggestive of the disorder. False positive results may occur if sodium metabisulphite of greater than $2 \%$ is used while false negative results may occur if the metabisulphite is stale and also in the neonatal period because of the low percentage of $\mathrm{HbS}$.

Solubility test. This is based on the fact that $\mathrm{HbS}$ is less soluble than $\mathrm{HbA}$ in the deoxygenated state. One drop of the patient's blood is mixed with a solution prepared using potassium dihydrogen phosphate, dipotassium hydrogen phosphate and sodium metabisulphite. The mixture is spun in a centrifuge; $\mathrm{HbS}$ if present, precipitates as a red opaque band on the surface of the test solution while other haemoglobins remain in solution ${ }^{6}$. Control blood samples with $\mathrm{HbA}, \mathrm{HbAS}$ and $\mathrm{HbS}$ should be tested at the same time. There are commercial test kits now available for this procedure. Solubility test should be performed on all samples which showed the "S" band on alkaline electrophoresis especially in our environment in which haemoglobins $G$ and $D$ which comigrate with $\mathrm{HbS}$ on alkaline electrophoresis is present.

\section{Haemoglobin Electrophoresis}

In an alkaline buffer, $\mathrm{HbA}$ is a negatively charged protein which moves toward the positive electrode (anode) in an electric field. Most haemoglobin variants are separated from $\mathrm{HbA}$ during electrophoresis because the structural abnormality usually involves changes in electrical charge while haemoglobin without a change in charge will not separate. The $\mathrm{pH}$ and medium used are varied in order to identify the different haemoglobin variants; electrophoresis for haemoglobin identification is commonly run with cellulose acetate paper at alkaline $\mathrm{pH}$ and/or citrate agar at acidic $\mathrm{pH}$.

Cellulose acetate electrophoresis at alkaline $p H$ : Cellulose acetate paper as support medium and at a $\mathrm{pH}$ of 8.48.9 has the advantage of rapid separation of haemoglobins, ease of handling and minimal prepara- tive work. Its disadvantages are that haemoglobin fractions in low concentration like $\mathrm{HbA} 2, \mathrm{HbH}$ and $\mathrm{Hb}$ Bart's may be missed. Also when small haemoglobin fractions occur near a broad band, the minor fraction may be missed especially in neonates when high levels of $\mathrm{HbF}$ can cause the presence of either $\mathrm{HbA}$ or $\mathrm{HbS}$ to be missed. Certain haemoglobins which comigrate at this $\mathrm{pH}$ include $\mathrm{HbS}, \mathrm{HbD}$ and $\mathrm{HbG}$, at this $\mathrm{pH}$ $\mathrm{HbA} 2, \mathrm{HbC}, \mathrm{HbE}$ and $\mathrm{HbO}$ also comigrate.

Citrate agar electrophoresis at acidic $p H$ : Separation of haemoglobin variants by this method is determined by the relative affinity for agaropectin by certain haemoglobin surface groups. It is performed at a $\mathrm{pH}$ of 6.0 6.2 and it delineates haemoglobins that comigrate at alkaline $\mathrm{pH}$ and other cases that cannot be resolved at alkaline $\mathrm{pH}$. It is particularly useful in diagnosing sickle cell disease at birth when the high concentration of $\mathrm{HbF}$ may pose a problem. It is however technically difficult to handle. Haemoglobins A,D,E,G, H all comigrate at this $\mathrm{pH}$.

Isoeletric focusing: This is a high resolution method for separating proteins according to their isoeletric points, i.e. points at which the net charge is zero. Separation of haemoglobins by this method is similar to that obtained by electrophoresis on cellulose acetate except that the bands are sharper and the resolution of some haemoglobins are better.

\section{Diagnosis of the Thalassaemias}

Red cell indices are particularly useful in screening for the thalassaemias and this is best done by an automated blood cell counter. Beta thalassaemia trait (BTT) is associated with mild or no anaemia but with reduced mean corpuscular volume (MCV), mean corpuscular haemoglobin $(\mathrm{MCH})$, values and an elevated haemoglobin $\mathrm{A}_{2}\left(\mathrm{HbA}_{2}\right)$ level ${ }^{7,8}$, normal red cell indices may however be found in people with thalassaemia trait ${ }^{9}$ or silent ${ }^{+}$trait $^{7}$. The diagnosis of thalassaemia is often made following exclusion of thalassaemia and/or iron deficiency; since most cases of alpha thalassaemia are of the clinically benign type (i.e. ${ }^{+}$thalassaemia). It should be noted that the red cell indices may also be affected by concomitant B12 deficiency, folate deficiency or liver abnormalities with such people having normal red cell indices. Also in the Nigerian population where the prevalence of alpha thalassaemia is equally high, normal red cell indices does not rule out Beta thalassaemia trait since there may not be the expected alpha/ beta chain imbalance.

To make a diagnosis of thalassaemia trait therefore, the following tests should be done (a) electrophoresis of haemoglobin on cellulose acetate membrane at al- 
kaline $\mathrm{pH}$; (b) measurement of $\mathrm{HbA}_{2}$; (c) assessment of $\mathrm{HbF}$; (d) checking for $\mathrm{HbH}$ inclusion bodies and (e) assessment of iron status.

Quantitative estimation of $\mathrm{Hb} \mathrm{A}_{2}$ : There are many methods for estimating $\mathrm{HbA} 2$ but the elution method after electrophoresis with cellulose acetate paper is still generally acceptable and reliable ${ }^{10}$. A raised $\mathrm{HbA}_{2}$ is the hallmark of the classic beta thalassaemia trait ${ }^{7}$. Any $\mathrm{HbA}_{2}$ variant present should be eluted with the $\mathrm{A}_{2}$. Values below 3.3\% are usually normal and over 3.7\% usually indicate the Beta thalassaemia trait. Overlap in $\mathrm{HbA}_{2}$ values between normal and Beta thalassaemia have been reported ${ }^{11}$, therefore values between 3.3 and $3.7 \%$ should be interpreted with care while a value above $7 \%$ suggests an analytical error or the presence of another haemoglobin that is not $A_{2}$. Concomitant iron deficiency may result in classifying a person with Beta thalassemia as not having the condition since iron deficiency may cause a low level of $\mathrm{HbA}_{2}{ }^{12}$, thus necessitating an assessment of the patient's iron status. The HbA2 should then be rechecked after iron therapy.

Assessment of HbF: This is traditionally measured by the two minute denaturation technique of Betke ${ }^{13}$. Recent methods include radial immunodiffusion, Eliza and by HPLC. HbF is below $1 \%$ in the healthy adult but values between $1-3 \%$ are found in a third to half of the patients with Beta thalassaemia trait ${ }^{7}$. A raised value of over $5 \%$ in the presence of hypochromia and microcytosis is suggestive of äâ thalassaemia but if the value of $\mathrm{HbF}$ is higher than $20 \%$ the distribution of the $\mathrm{HbF}$ in the cell is checked for by Kleihauer cytochemical test. This will help differentiate High persistence of $\mathrm{HbF}$ (HPHF) from thalassaemia.

HB H inclusion bodies: The presence of $\mathrm{Hb} \mathrm{H}$ inclusion bodies is better observed in slides prepared from fresh blood stained with supravital stains like brilliant cresyl blue or new methylene blue and it indicative of alpha thalassaemia. Red cells with inclusion bodies are fewer in people with alpha thalassaemia trait than in people with $\mathrm{Hb} \mathrm{H}$ disease. The absence of $\mathrm{Hb} \mathrm{H}$ inclusion does not, however, exclude an alpha thalassaemia trait.

Iron status: Iron deficiency anaemia is a differential diagnosis of hypochromic, microcytic anaemia; it can also be a reason for a low $\mathrm{HbA}_{2}$ in a patient with beta thalassaemia trait. It may therefore be necessary to know the iron status of a patient suspected of having thalassaemia trait. Red cell indices and formulae derived from them have not been useful in differentiating between beta thalassaemia trait and iron deficiency $^{8,14,15}$. Studies done in the Nigerian population have shown normal iron levels in healthy, pregnant women and sickle cell disease patients ${ }^{16,17}$ so hypo- chromic microcytic cells in peripheral blood film review should not be assumed to be due to iron deficiency when iron studies have not been done.

Globin Chain Synthesis: This technique quantifies the amount of alpha and beta chains ( / ratio) by culturing peripheral blood reticulocytes in the presence of tritiated leucine. It helps to determine if there is an imbalance in the ratio of synthesis of the two globin chains. This test is better done in a reference laboratory with facilities for the use and disposal of radioactive materials. The ratio is less than one in alpha thalassaemia and greater than one in beta thalassaemia.

High Performance Liquid Chromatography (HPLC): This is an advanced technology used in separating the components of a mixture; it can thus be used to separate and quantify haemoglobins. For the analysis of haemoglobin variants, weak cation and anion-exchange columns are used while a reversed phase column are used for globin chain analysis. HPLC can be used primarily as a screening method or as a supplement to electrophoresis. The high cost is a disadvantage to the use of HPLC even though its results are reliable and reproducible; there could also be the technical problem of coeluting other haemoglobins with $\mathrm{HbA}_{2}$ especially in the hands of the inexperienced.

\section{Molecular Methods in the Diagnosis of Haemoglobinopathies} DNA analysis in the diagnosis of haemoglobinopathies even though undertaken in specialist referral centres is not done as a routine but mostly employed in prenatal diagnosis and in resolving diagnosis of difficult cases of haemoglobinopathies. Specimen for DNA analysis is obtained from white cells, chorionic tissue or amniocytes. Each mutation is detected by its own specific probes or primers. DNA analyses are based on Southern blot analysis or polymerase chain reaction (PCR) with emphasis shifting towards the use of PCR based techniques, Southern blot are still necessary in some situations. The three PCR based techniques used in diagnostic laboratories include (a) the hybridization of labelled allele specific oligonucleotide probes, to amplified DNA fixed to nylon filters by dot blotting ${ }^{18}$ or by reverse dot blotting with the probes fixed to the filters ${ }^{19}$; (b) the use of allele specific primers $^{20}$; and (c) agarose or polyacrylamide gel electrophoresis. The first two techniques detect point mutations and require a battery of specific probes one for every mutation likely to be encountered. There are many sources of errors with the use of the PCR which include contamination from previous samples or maternal contamination, non amplification of a desired segment and incomplete digestion of amplified product. Samples should therefore be handled with utmost care. 


\section{CONCLUSION}

Primary health care facilities are closest to the communities; so should be able to screen for the haemoglobinopathies. Therefore, every patient presenting with a haematocrit less than $30 \%$ should be referred for secondary care, so also should all patients found to have a positive sickling test. These centres should have facilities to check the haematocrit of patients and a microscope for the sickling test. The staff should be trained to use the microscope for a sickling test and to check for hypochromia and microcytosis. Every general hospital on the other hand should be able to run electrophoresis at alkaline $\mathrm{pH}$ and have an automated cell counter to check the red cell indices of patients. Staff at these hospitals should also be able to interpret results from both equipment. While at the tertiary level, citrate agar electrophoresis or isoelectric focusing should be mandatory with DNA technology provided at designated tertiary centres in the geopolitical zones. Accurate diagnosis of the haemoglobinopathies is important in this community with a high prevalence of the sickle cell and thalassaemia syndromes. Each hospital should have technical staffs that are well trained to handle the specimens and should be able to decide when to refer diagnosis to a higher facility when difficulty arises. The need for quality control is also essential in the diagnosis of the haemoglobinopathies; apart from the inbuilt quality control of each procedure, laboratories should be a part of other external quality control programs.

\section{REFERENCES}

1. Omotade O.O., Kayode C.M., Falade S.L. et al. Routine screening for sickle cell haemoglobinopathy by electrophoresis in an infant welfare clinic. West Afr J Med 1998;17:91-94

2. Falusi A.G., Esan G..J and Ayubb H. Alpha thalassaemia in Nigeria: its interaction with sickle cell disease. Eur J Haematol.1987;38:370-375

3. Esan G.J.F. The thalassaemia syndrome in Nigeria. Br J Haematol. 1970;19:47-56

4. Kotila T.R. When the inheritance of two heterozygote states become a diagnostic problem: Misdiagnosis of the sickle cell trait. Nig J Med 2007;16:14

5. Kotila T.R., Adeyemo A.A., Mewoyeka O.O. and Shokunbi W.A. Beta thalassaemia trait in Western Nigeria. Afr Health Sci 2009;9:46-48

6. Esan G.J.F. The essential laboratory investigation of sickle cell disease. In: sickle cell disease: A hand- book for the general clinician. Ed AF Fleming. Edinburgh: Churchill Livingstone, 1982:33-41

7. British Committee for Standards in Haematology. Guidelines for investigation of the and thalassaemia traits. J Clin Pathol 1994;47:289295

8. Rathod A.A., Kaus A., Patel V. et al. Usefulness of cell counter based parameters and formulars in detection of thalassaemia trait in areas of high prevalence. Am J Pathol. 2007;128:585-589

9. Weatherall D.J., Clegg J.B. The thalassaemia syndromes. $3^{\text {rd }}$ edn. Oxford: Blackwell Sci Publications, 1981

10. International Committee for Standardization in Haematology. Recommendations for selected methods for quantitative estimstion of $\mathrm{HbA} 2$ and for $\mathrm{HbA} 2$ reference preparation. Br J Haematol. 1978;38:573-577

11. Efremov G.D. In: Huisman THJ, ed. Methods in Haematology No 15: the haemoglobinopathies. Edinburgh: Churchill Livingstone, 1986:72-90

12. Alperin J.B., Dow P.A. and Petteway M.B. Haemoglobin A2 levels in health and various haematological disorders. Am J Clin Pathol 1972;67:219-26

13. Betke K., Marti H.R. and Schlicht I. Estimation of small percentage of fetal haemoglobin. Nature 1959; 184:1877-1878

14. Okan V., Cigiloglu A. and Cifa S. Red cell indices and functions differentiating patients with the beta thalassaemia trait from those of iron deficiency anaemia. J Int Med Res. 2009;37:25-30

15. Beyan C., Kaptan K. and Ifran A. Predictive value of discriminating indices in differential diagnosis of iron deficiency and beta thalassaemia trait. Eur J Haematol. 2007;78:524-526

16. Oluboyede O.A., Usanga E.A., Lukanmbi F.A.and Ajayi O.A. Evaluation of serum ferritin levels and other hematological parameters in a Nigerian population. J Natl Med Assoc. 1983; 75:885-889

17. Abudu O.O., Macaulay K. and Oluboyede O.A. Serial evaluation of iron stores in pregnant Nigerians with hemoglobin SS or SC. J Natl Assoc.1990; 82:41-48 
18. Saiki R.K., Bugawan T.L., Horn G.T., et al. Analysis of enzymatically amplified globin and HLADQ alpha DNA with allele -specific oligonucleotide probes. Nature 1986;324:163-166

19. Saiki R.K., Walsh P.S., Levenson C.H., et al. Genetic analysis of amplified DNA with immobilized sequence specific oligonucleotide probes. Proc Natl Acad Sci USA 1989;86:6230-6234
20. Old J.M., Varawalla N.Y. and Weatherall D.J. The rapid detection and prenatal diagnosis of thalassemia in the Asian Indian and Cypriot populations in the UK. Lancet 1990;ii:834-837 